Revista Brasileira de Meteorologia, v.27, n.3, 315 - 328, 2012

\title{
ESTIMATIVAS DE UM MODELO DE GERAÇÃO E PROPAGAÇÃO DE ONDAS EMPREGANDO CAMPOS DE VENTO COM DIFERENTES RESOLUÇÕES ESPACIAIS E TEMPORAIS
}

\author{
FREDERICO FRANCISCO OSTRITZ ${ }^{1}$, NELSON VIOLANTE DE CARVALHO ${ }^{1}$, LEONARDO \\ MATURO MARQUES DA CRUZ ${ }^{2}$ \\ ${ }^{1}$ Universidade Estadual do Rio de Janeiro (UFRJ), Rio de Janeiro, RJ, Brasil \\ ${ }^{2}$ PROOCEANO, Rio de Janeiro, RJ, Brasil \\ fredostritz@gmail.com, violante_carvalho@yahoo.co.uk, leonardo@prooceano.com.br
}

Recebido Maio de 2010 - Aceito Janeiro de 2012

\begin{abstract}
RESUMO
O presente trabalho apresenta uma comparação entre algumas rodadas do modelo numérico de geração e propagação de ondas Wavewatch III empregando campos de vento com diferentes resoluções espaciais e temporais em uma região tropical do oceano Atlântico Sul. Os campos de vento utilizados de entrada são os da Reanálise do NCEP (com resolução espacial de cerca de $2^{\circ}$ e resolução temporal de 6 horas), do Global Forecast System (resolução espacial de $1^{\circ}$ e resolução temporal de 6 horas), bem como os campos de maior resolução espacial e temporal de um modelo de mesoescala (Mesoscale Modeling System), com resolução espacial de $0,2^{\circ}$ e resolução temporal de 1 e 6 horas. As estimativas de altura significativa, período de pico e direção principal de propagação do Wavewatch III, assim como as estimativas dos ventos usados como entrada, são comparadas com as medições de ondas de um radar e de um anemômetro, ambos instalados na Bacia de Campos, sudeste do Brasil. Os resultados mostram que campos de vento com maior resolução espacial têm um impacto positivo sobre a previsão das ondas. No entanto, mantendo a mesma resolução espacial e aumentando a resolução temporal, não se obtém melhores estimativas dos campos de onda.
\end{abstract}

\begin{abstract}
ESTIMATIVES OF A GENERATION AND PROPAGATION WAVE MODEL USING WIND FIELDS AT DIFFERENT SPATIAL AND TEMPORAL RESOLUTION

This work presents a comparison among several runs of the numerical wave model, Wavewatch III (WW3) employing different temporal and spatial resolutions for the wind fields in a tropical area of the Southern Atlantic Ocean. The input wind fields are from the National Centers for Environmental Prediction (NCEP) reanalysis, with $2^{\circ}$ spatial resolution and 6 hours temporal resolution, the Global Forecast System (GFS) analysis, with $1^{\circ}$ spatial resolution and 6 hours temporal resolution, as well as the higher spatial and temporal resolution fields of a mesoscale model (Mesoscale Modeling System), with $0.2^{\circ}$ spatial resolution and temporal resolution of 1 and 6 hours. The WW3 estimates of significant wave height, peak period and main propagation direction, as well as the wind estimates used as input, are inter-compared against a radar wave measurements and wind speed and direction recorded from an anemometer, both instruments operating on board at an oil platform in the Campos Basin, south-eastern Brazil. The results show that a higher spatial resolution for the wind input has a positive impact on the wave estimates. However, maintaining the same spatial resolution and increasing the temporal resolution does not translate into significantly better wave estimates.
\end{abstract}

Keywords: Wind Waves; Campos Basin; Wave Modeling 


\section{INTRODUÇÃO}

Estimar as condições do mar através das características das ondas superficiais faz parte de um conjunto de diretrizes que prezam não somente pelo sucesso em projetos de engenharia, como também pela segurança em atividades marítimas. Adicionalmente, atividades lúdicas como o surfe, windsurfe e vela também são extremamente beneficiadas com uma boa previsão.

Neste contexto, modelos numéricos vêm sendo desenvolvidos há aproximadamente 50 anos, cujos avanços contínuos resultaram nos atuais modelos de terceira geração (Komen et al., 1994). Entre eles estão o WAM (WANDI Group, 1998) e WAVEWATCH III (Tolman, 2002), cujo desempenho é bastante satisfatório, especialmente para regiões oceânicas e não abrigadas (Ardhuin et al., 2007; Cavaleri e Bertotti, 2006).

O principal agente formador das ondas de gravidade é o vento atuando sobre a superfície do mar. Assim, a qualidade das estimativas feitas pelo modelo está intimamente relacionada à qualidade do campo de vento empregado na simulação. Trabalhos como os de Teixeira et al. (1995) e Holthuijsen et al. (1996), mostram que erros nas estimativas do vento são uma das principais causas das incertezas nas estimativas das ondas.

Os campos de vento utilizados por modelos de geração e propagação de ondas são geralmente obtidos de modelos meteorológicos. Atualmente, modelos meteorológicos apresentam bons resultados principalmente em regiões oceânicas. Em regiões costeiras, onde o vento em superfície é afetado pela orografia, ocorre uma subestimação por parte de tais modelos (Cavaleri e Bertotti, 2006).

Com o intuito de realizar previsões de onda cada vez melhores, uma série de trabalhos vem demonstrando a sensibilidade dos modelos de geração e propagação de ondas a diferentes campos de vento (Rusu et al., 2009; Bauer e Weisse, 2000; Teixeira et al., 1995). Os resultados mostram que a utilização de ventos com alta resolução espacial e temporal gera impactos positivos na estimativa das ondas, principalmente em relação à altura significativa.

Feng et al. (2006) avaliam o desempenho do modelo Wavewatch III (WW3) empregando quatro campos de vento com diferentes resoluções espaciais e temporais, incluindo os provenientes da Reanálise/NCEP (National Centers for Environmental Prediction) e do escaterômetro QuickSCAT. As estimativas foram comparadas a dados altimétricos do satélite TOPEX e foi observado, que em termos de altura significativa, a Reanálise/NCEP apresentou melhores resultados, apesar da menor resolução espacial e temporal. Os autores atribuem este resultado ao fato da versão do WW3, utilizada na simulação, ter sido desenvolvida baseada nos ventos da Reanálise/NCEP. Adicionalmente, tais autores concluem que o uso de ventos com alta resolução espacial e temporal conduz a melhoras em momentos espectrais de ordem mais alta.

Marques da Cruz (2004) empregou ao WW3 os ventos da Reanálise/NCEP e do AVN (Aviation Forecast), onde foram obtidos resultados bastante semelhantes entre as duas simulações. Ao compará-los com dados medidos por um ondógrafo instalado em Arraial do Cabo (sudeste do Brasil), verificou-se uma boa representação do estado do mar, principalmente para ondulação. Ambas as simulações geraram resultados bastante semelhantes apesar de uma ligeira subestimação em relação à medição, sobretudo por parte das estimativas empregando a Reanálise/ NCEP, cuja resolução espacial é inferior.

Resumidamente, sem a utilização de um campo de vento de boa qualidade, modelos numéricos de geração e propagação de ondas não irão gerar bons resultados, ainda que representem o problema físico de forma bastante satisfatória sob diversos estados de mar. Cavaleri e Bertotti (2006) e Ardhuin et al. (2007) ressaltam as limitações dos modelos em simular estados de mar sob condições extremas, atribuindo estas falhas à representação física das ondas nesses eventos. Segundo estes autores, a teoria clássica de geração de ondas, desenvolvida por J. W. Miles e suas subseqüentes modificações, ainda não são suficientes para representar corretamente estados de mar gerados por tempestades. Adicionalmente, tais autores apontam para deficiências dos referidos modelos na representação da transferência não linear de energia e perda por white-capping sob estas condições.

Descrito tal cenário, o presente trabalho tem por objetivo verificar a sensibilidade de um modelo de geração e propagação de ondas a diferentes campos de vento diferenciados pelas suas resoluções espaciais e temporais. As restrições da representação da física dos modelos citadas anteriormente não são contempladas, limitando o presente na avaliação do impacto do campo de ventos, um dos muitos aspectos cruciais na modelagem de ondas. O modelo selecionado neste trabalho é o WW3, versão 2.22. São realizadas quatro simulações utilizando diferentes campos de vento como forçantes abrangendo o período de $1^{\circ}$ de janeiro de 2008 a 12 de fevereiro de 2008 .

A área de interesse deste trabalho é a Bacia de Campos (sudeste do Brasil), marcada por diversas operações offshore, fruto de intensa atividade petrolífera. Ventos intensos durante o verão ocorrem de forma marcante nesta região, sendo responsáveis por eventos mais energéticos associados à alta freqüência ViolanteCarvalho et al. (1997a). Já as ondulações, caracterizadas pela maior energia em baixa freqüência, estão presentes ao longo de todo o ano, como demonstrado por Violante-Carvalho et al. (1997b). Tais características fazem do verão uma estação bastante interessante para simulações numéricas.

A acurácia das simulações é testada através da comparação dos resultados, em termos de altura significativa $\left(H_{s}\right)$, período de pico $\left(T_{p}\right)$ e direção principal associado ao $T_{p}$ 
$\left(D_{p}\right)$, com medições feitas por um radar instalado na referida região. Da mesma maneira, a qualidade dos campos de vento também é verificada através de medições feitas por um anemômetro instalado no mesmo local.

Este trabalho é divido da seguinte forma: breve descrição dos campos de vento utilizados (seção 2.1); apresentação das configurações utilizadas no modelo (seção 2.2); sucinta descrição do radar Miros (seção 2.3); descrição dos parâmetros estatísticos usados para validação dos resultados obtidos (seção 2.4); resultados e discussão (seção 3) e conclusão (seção 4).

\section{MATERIAIS E MÉTODOS}

\subsection{Campos de vento}

São utilizados no presente estudo quatro campos de vento para alimentar o WW3, cujas especificações se encontram na Tabela 1.

O primeiro campo de vento utilizado é produto do modelo atmosférico fruto de uma cooperação entre o NCEP e o NCAR (National Center for Atmospheric Research), denominado Reanálise. Este é um modelo espectral que utiliza um esquema tridimensional de análise variacional assimilando dados medidos de diversas origens como satélites, observações de navios e aviões, bóias, entre outras. Uma vez coletados, tais dados passam por um rigoroso controle de qualidade até estarem prontos para assimilação. As componentes zonais e meridionais de vento a dez metros são disponibilizadas a cada 6 horas com resolução espacial de $1,875^{\circ}$ em longitude e por volta de $1,9^{\circ}$ em latitude. Maiores informações a respeito da Reanálise do NCEP, podem ser encontradas em Kistler et al. (2001) e Kalnay et al. (1996).

O segundo campo de vento utilizado é oriundo do Global Forecast System (GFS), um modelo numérico de previsão mantido pela NOAA (National Oceanic and Atmospheric Administration), bem semelhante à Reanálise/NCEP. São disponibilizadas quatro vezes ao dia (00 UTC, 06 UTC, 12 UTC e 18 UTC) a previsão para 16 dias das componentes zonais e meridionais do vento. Durante o período selecionado eram disponibilizas saídas com resolução de até T382 $(35 \mathrm{~km})$. No entanto, para o presente estudo foram selecionados os campos de vento com resolução espacial mais grosseira $\left(1^{\circ} \times 1^{\circ}\right)$, uma vez que seria empregado o campo de ventos do MM5, que apresenta resolução da mesma ordem que T382. Durante o período da simulação, foram selecionadas as primeiras 24 horas das previsões disponibilizadas às 00 UTC de cada dia, de modo a ter uma continuidade dos dados. Mais informações acerca deste modelo podem ser encontradas no link http://www.emc. ncep.noaa.gov/GFS/.

Já o terceiro e quarto campos de vento foram gerados pelo modelo de quinta geração MM5 (Mesoscale Model). Desenvolvido no início dos anos 70, numa parceria da Pensylvania State University com o NCAR, o MM5 é um modelo numérico de previsão de circulação atmosférica em escalas regionais e mesoescala. O sistema MM5 possui uma estrutura modular, composta por alguns programas auxiliares, responsáveis pelo pré-processamento de dados meteorológicos e terrestres antes que a simulação seja iniciada. Além de ter a capacidade de realizar múltiplos aninhamentos, dinâmica não hidrostática e assimilação de dados em quatro dimensões, este modelo apresenta várias parametrizações físicas (microfísica, convecção, camada limite planetária, radiação e temperatura de solo) e portabilidade em diversas plataformas computacionais.

Diferentemente da Reanálise/NCEP e do GFS, o MM5 utiliza um sistema de coordenadas que segue a topografia, resolvendo numericamente as equações primitivas por diferenças finitas no espaço e no tempo. Tais modelos são espectrais, ou seja, as variáveis contínuas são discretizadas através da transformada rápida de Fourier e quadratura Gaussiana a cada passo de tempo e convertidas de volta para o espaço espectral, via transformada de Legendre e transformada inversa de Fourier.

O MM5, através da grade Arakawa-B, resolve as variáveis de quantidade de movimento pontos de grade, enquanto as variáveis escalares são resolvidas no interior da célula da grade. A coordenada vertical utilizada no modelo é a sigma-P, no qual os níveis mais baixos se aproximam do terreno e os níveis mais altos tendem a aproximar-se de superfícies isobáricas. No presente estudo foram utilizados quatros desses módulos (Terrain, Regrid, Interpf e MM5) que, apesar de não refletirem todas as potencialidades do modelo, o tornam capaz de gerar

Tabela 1 - Características dos ventos utilizados

\begin{tabular}{ccccc}
\hline & $\begin{array}{c}\text { Reanálise do } \\
\text { NCEP/NCAR }\end{array}$ & $\begin{array}{c}\text { Global Forecast } \\
\text { System (GFS) }\end{array}$ & $\begin{array}{c}\text { Mesoscale } \\
(\text { MM5 })\end{array}$ & $\begin{array}{c}\text { Model } \\
\text { (MM5) }\end{array}$ \\
\hline $\begin{array}{c}\text { Resolução } \\
\text { Espacial }\end{array}$ & $1,875^{\circ} \times 1,900^{\circ}$ & $1^{\circ} \times 1^{\circ}$ & $0,22^{\circ} \times 0,2^{\circ}$ & $0,2^{\circ} \times 0,2^{\circ}$ \\
$\begin{array}{c}\text { Resolução } \\
\text { Temporal }\end{array}$ & 6 horas & 6 horas & 6 horas & 1 hora \\
Domínio & $\begin{array}{c}\text { Lat : } 0^{\circ} \text { a }-77^{\circ} \\
\text { Lon: }-101^{\circ} \text { a } 30^{\circ}\end{array}$ & $\begin{array}{c}\text { Lat : } 0^{\circ} \text { a }-77^{\circ} \\
\text { Lon: }-101^{\circ} \text { a } 30^{\circ}\end{array}$ & $\begin{array}{c}\text { Lat : }-27^{\circ} \text { a }-10^{\circ} \\
\text { Lon: }-50^{\circ} \text { a }-32,5^{\circ}\end{array}$ & $\begin{array}{c}\text { Lat : }-27^{\circ} \text { a }-10^{\circ} \\
\text { Lon: }-50^{\circ} \text { a }-32,5^{\circ}\end{array}$ \\
\hline
\end{tabular}


campos de vento com características de mesoescala. Detalhes do modelo estão disponíveis em http://www.mmm.ucar.edu/mm5/.

Os campos de vento gerados pelo modelo MM5 correspondem à região sudeste do Brasil e são fruto de um aninhamento utilizando resultados do GFS (abrangendo todo o Atlântico) como condições de contorno. Com intuito de avaliar a contribuição da resolução temporal nas estimativas do WW3, foram gerados dois campos de vento com a mesma resolução espacial de $0,2^{\circ} \times 0,2^{\circ}$ e diferentes resoluções temporais: um atualizado a cada seis horas e outro a cada hora.

\subsection{Configurações das simulações do WW3}

O modelo de geração e propagação de ondas WW3 é um modelo de terceira geração baseado no trabalho realizado pelo WAM group e desenvolvido pela NOAA (Tolman, 2002). Este modelo resolve a equação de balanço do espectro de energia de ação em função do número de onda e da direção. A parametrização dos termos de ganho e dissipação de energia, bem como a representação das interações não lineares utilizadas neste estudo são a proposta por Tolman e Chalikov (1996) e a Discrete Interaction Approximation (DIA, Hasselman et al., 1985), respectivamente. No presente trabalho são realizadas quatro simulações empregando os quatro campos de vento citados anteriormente.

Na simulação utilizando o campo de vento da Reanálise/ NCEP, o WW3 é configurado com uma resolução espacial de $0,5^{\circ} \times 0,5^{\circ}$ cujo domínio abrange a mesma região do vento (Tabela 1). A configuração dos passos de tempo é listada na Tabela 2. A batimetria utilizada nesta simulação é oriunda da base de dados Etopo5 (disponível em http://www.ngdc.noaa. gov/mgg/gdas) e interpolada linearmente para a resolução de $0,5^{\circ} \times 0,5^{\circ}$.

Esta mesma configuração do modelo de ondas é utilizada na simulação empregando os ventos do GFS. Todavia, nesta simulação são geradas as condições de contorno para posteriores aninhamentos do WW3 empregando os ventos do MM5.
Em tais aninhamentos, as condições de contorno geradas pelo WW3 empregando os ventos do GFS são aplicadas nas bordas das grades de maior resolução, onde são utilizados os ventos gerados pelo MM5. O domínio de grade destas simulações é a região sudeste do Brasil, cujos limites são o mesmo dos campos de vento utilizados (Tabela 1), porém com resolução espacial de cinco minutos. A batimetria utilizada nesta simulação também é obtida através da base de dados Etopo5 e a configuração dos passos de tempo utilizados se encontram na Tabela 2 .

Em todas as simulações o modelo é configurado para gerar saídas de altura significativa a cada hora cheia. A grade espectral é discretizada com 24 direções e 25 freqüências (iniciando em $0,042 \mathrm{~Hz}$ com incremento dado na forma de progressão geométrica de razão $1,124 \mathrm{~Hz}$ ). Os dados referentes aos três primeiros dias de cada simulação são descartados para “aquecer" o modelo ( $\operatorname{cpin}$ up). Este período é função do tempo mínimo necessário para que as ondulações geradas mais longinquamente, em geral no extremo sul da América do Sul, atinjam a Bacia de Campos.

\subsection{O radar Miros}

O Miros é um sensor especialmente desenvolvido para estimar o espectro direcional de ondas, bem como intensidade e direção da corrente superficial. Baseado em técnicas avançadas de sensoriamento remoto por microondas, este radar é composto por uma antena, um transmissor, um receptor e um processador de imagens.

Posicionada quase horizontalmente, a antena emite pulsos eletromagnéticos com ângulo de incidência inferior a $10^{\circ}$, que são então refletidas pela superfície do mar. $\mathrm{O}$ pulso emitido é retro-espalhado com amplitude e fase moduladas pela interação entre as ondas eletromagnéticas e as ondas do mar. Basicamente, o sinal que retorna ao equipamento é modulado devido a três processos principais: inclinação da superfície (tilt modulation), modulação hidrodinâmica (hydrodinamic

Tabela 2 - Configuração dos passos de tempo utilizados nas simulações

\begin{tabular}{lcc}
\hline \multicolumn{1}{c}{ Passo de Tempo } & $\begin{array}{c}\text { Simulações empregando } \\
\text { ventos do GFS/ Reanálise } \\
\text { (segundos) }\end{array}$ & $\begin{array}{c}\text { Simulações empregando } \\
\text { ventos do MM5 } \\
\text { (segundos) }\end{array}$ \\
\hline $\begin{array}{l}\text { Global (máximo no termo } \\
\text { fonte de integração) } \\
\text { Mínimo no termo fonte de }\end{array}$ & 900 & 180 \\
integração & 300 & 60 \\
Máximo de propagação & 900 & 180 \\
Refração & 90 & 20 \\
\hline
\end{tabular}


modulation) e o deslocamento vertical da superfície (velocity bunching modulation).

A inclinação da superfície (causada pelas ondas de gravidade) afeta o sinal de retorno uma vez que muda ângulo de visada das ondas capilares. De maneira geral, a quantidade de energia refletida é maior quando a face da onda de gravidade está posicionada na direção do radar, e diminui à medida que a superfície se inclina no sentido oposto.

Já a modulação hidrodinâmica se dá através das correntes induzidas pela velocidade orbital das ondas de maior comprimento. A velocidade orbital dessas ondas gera zonas de convergência (próximas à crista) e divergência (próximas ao cavado) na superfície do oceano. Portanto, durante a passagem de uma crista de uma onda de gravidade, as ondas capilares sofrem um aumento na amplitude. De forma análoga, elas sofrem uma diminuição na amplitude durante a passagem de um cavado.

Finalmente, quando um pulso emitido é refletido por um objeto movendo-se com velocidade relativa ao sensor, a freqüência do eco sofrerá uma mudança em relação à freqüência do sinal transmitido (efeito Doppler). Na superfície do mar, o deslocamento vertical sofrido pelas ondas capilares (induzido pela velocidade orbital das ondas maiores), faz dessas um alvo móvel para o sensor, modulando o sinal que retorna para o mesmo (velocity bunching modulation).

Dessa forma, a modulação do sinal refletido forma a base para o sensoriamento remoto da superfície do mar por microondas, proporcionando informações a partir de uma análise sofisticada deste sinal. Operando na freqüência dentro da banda $\mathrm{C}$ (intervalo entre $3,9 \mathrm{GHz}$ e $5,75 \mathrm{GHz}$ ), este equipamento garante um bom desempenho, mesmo sob condições adversas, como spray marinho e precipitação. Além disso, o fato de o radar utilizar sua própria fonte de energia permite a operação independente da iluminação solar.

Este trabalho utiliza as séries temporais de $\mathrm{Hs}$, Tp e Dp medidas pelo aparelho durante o período de $1^{\circ}$ janeiro de 2008 a 12 de fevereiro de 2008.

\subsection{Parâmetros Estatísticos aplicados para a avaliação do WW3 e dos campos de vento utilizados}

Com o intuito de avaliar a qualidade dos campos de vento estimados pelos modelos meteorológicos e o desempenho do WW3 durante as quatro simulações, parâmetros estatísticos como média e coeficiente de correlação são calculados para comparar as estimativas de altura significativa e intensidade do vento com as respectivas medições. Parâmetros como o erro médio quadrático (RMSE), viés e índice de espalhamento (SI) também são calculados, cujas fórmulas são apresentadas abaixo:

$$
\text { Viés }=\frac{1}{n} \sum(E-M)
$$

$$
\begin{aligned}
& R M S E=\sqrt{\frac{\sum(E-M)^{2}}{n}} \mathrm{e} \\
& S I=\frac{R M S E}{A}
\end{aligned}
$$

onde $\mathrm{n}, \mathrm{A}, \mathrm{M}$ e E são o número de elementos, a média dos dados medidos, a série de dados medidos e a série de dados estimados, respectivamente. $\mathrm{O}$ valor dos referidos parâmetros são resultados da comparação de séries temporais medidas e modeladas de onda e vento contendo 955 elementos cada.

\section{RESULTADOS}

Com o objetivo de facilitar a apresentação dos resultados, abreviaturas são usadas para representar os campos de vento, bem como as saídas do WW3. Os campos de vento da Reanálise/ NCEP, do GFS, do MM5 atualizado a cada seis horas e MM5 atualizado a cada hora são representados respectivamente por RNS, GFS, MM56 e MM51. De forma análoga, WRNS, WGFS, WMM56 e WMM51 indicam as estimativas do WW3 empregando os campos de vento RNS, GFS, MM56 e MM51, respectivamente.

\subsection{Avaliação dos campos de vento}

A avaliação da qualidade dos campos de vento utilizados neste estudo é realizada através da comparação entre a medição de um anemômetro e valores pontuais dos campos de vento coincidentes com a localização do aparelho. Tais valores são obtidos por meio de uma interpolação linear dos campos de vento realizada pelo WW3. A seguir, são apresentadas as séries temporais de intensidades e direções dos ventos estimados e medidos (Figura 1).

Nesta figura é possível observar ventos mais intensos, predominantemente, de quadrante norte, bem como a presença de ventos mais amenos de Sul. Nesta região, os ventos de nordeste são devido ao Anticiclone Subtropical do Atlântico Sul (ASAS), um sistema de alta pressão semi-permanente, cuja oscilação mais marcante ocorre de forma sazonal. Durante o verão, tal sistema se desloca para sudeste, fazendo com que os ventos se intensifiquem nas direções N-NE. Já no inverno, em função de encontrar-se mais inserido sobre o continente, o ASAS apresenta ventos de N-NE menos intensos devido ao atrito com a superfície. Em ambas as estações, os ventos giram no sentido anti-horário durante a passagem de uma frente fria, mudando sua direção para S-SE. Esta característica pode ser vista durante os dias 07/01, 21/01 e 04/02, aproximadamente. Este padrão já foi reportado por diversos autores, tais como, Pinho (2003) e Violante-Carvalho et al.(1997a). 

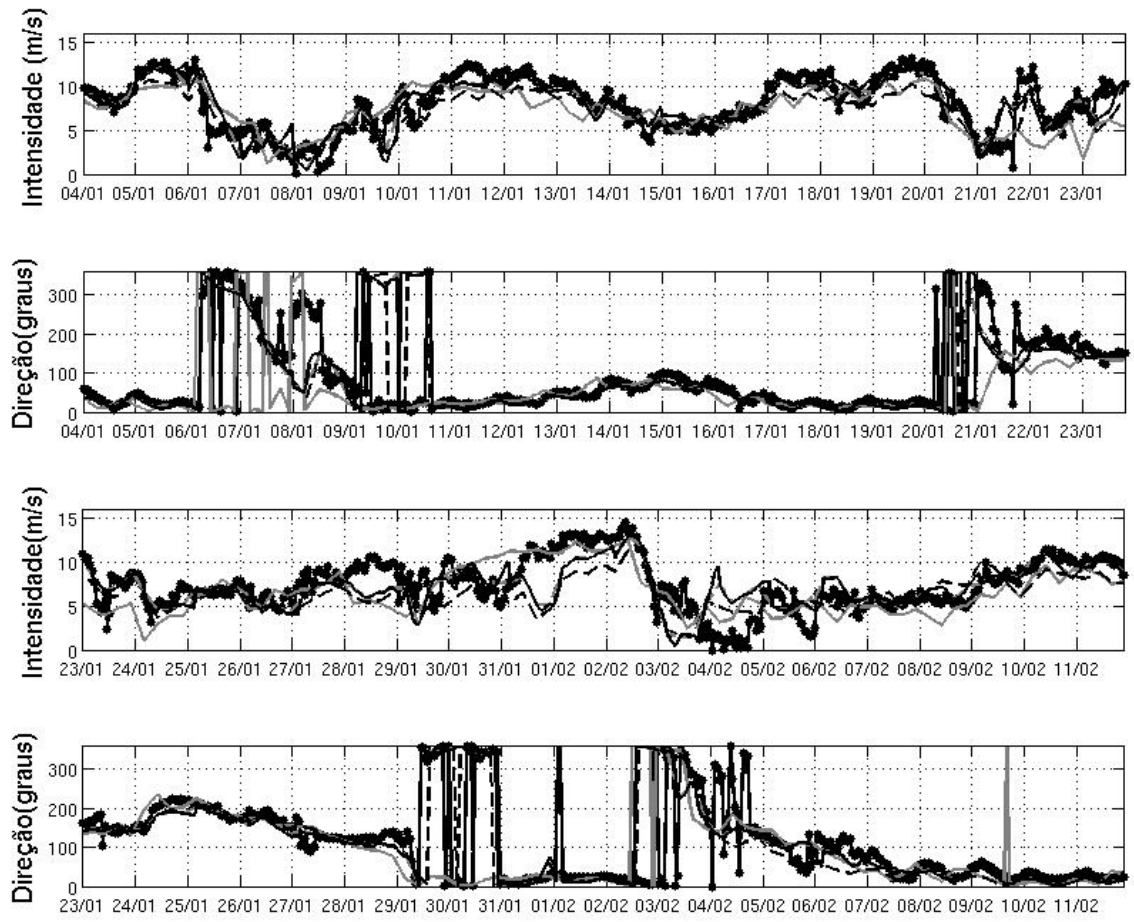

$\longrightarrow$ Medição — RNS --- GFS --- MM56 - MM51

Figura 1 - Evolução temporal da intensidade e direção dos ventos estimados e medido.

Menezes (2007) ao analisar medições feitas por um anemômetro instalado em Macaé (região sudeste do Brasil) encontrou resultados semelhantes, onde intensidades do vento entre 10 e $15 \mathrm{~m} / \mathrm{s}$ são associados às direções N-NE.

No que tange ao desempenho dos modelos, apesar de uma ligeira subestimação em relação à medição, observa-se que todos apresentam um resultado satisfatório, especialmente quando a região esteve sob influência do ASAS. Entradas de frente frias, no entanto, não são simuladas com o mesmo êxito, como percebemos durante os dias 21/01 e 04/02, especialmente por parte da RNS. Isto pode ser corroborado observando a comparação das séries de direção entres os dias 29/01 e 31/01, onde esta última não identifica a variação que ocorre em torno da direção norte, como fica evidente nas demais séries.

Como discutido por Marques da Cruz (2004), uma possível causa para esta observação se deve ao fato de ciclones extra-tropicais serem mal representados pelos campos de vento, principalmente o RNS, devido à sua baixa resolução espacial e um número menor de medições usadas na assimilação no hemisfério sul. Adicionalmente, a Figura 1 mostra que o MM51 e MM56 são praticamente idênticos, sugerindo que o aumento da resolução temporal do modelo não conduz a resultados mais satisfatórios. Vale também ressaltar a semelhança entre esses ventos e o GFS, refletindo o fato deste ter sido utilizado como condições de contorno para gerar o MM51 e MM56.
A Tabela 3 resume os valores dos parâmetros estatísticos calculados utilizando séries de 955 valores.Observando a Tabela 3, o viés negativo indica que de forma geral os modelos subestimam os valores de vento medido, como ilustrado na Figura 1. Dentre os modelos, o GFS e o MM56 apresentam o maior e menor valor de viés, respectivamente. No que se refere à correlação, os resultados se apresentaram bastante semelhantes, mostrando que o aumento da resolução espacial e temporal conduz a uma melhora nos resultados da ordem de 7\%, com o MM56 apresentando melhores resultados. Cavaleri e Bertotti (2006) comparam campos de vento do modelo ECMWF com diferentes resoluções espaciais a 36 bóias espalhadas no Pacífico e Atlântico Norte, mostrando que o aumento da resolução de $188 \mathrm{~km}$ para $25 \mathrm{~km}$ acarretou em um decréscimo do viés de $-0,16 \mathrm{~m}$ para $0,01 \mathrm{~m}$, respectivamente.

A Tabela 3 mostra valores de erro médio quadrático e índice de espalhamento em torno de $2 \mathrm{~m} / \mathrm{s}$ e 0,3 , respectivamente, sendo o RNS o que apresentou os maiores valores. Tais informações podem ser melhor observadas na Figura 2, onde são apresentados os diagramas de espalhamento de intensidades do vento referentes a cada campo de ventos utilizados.

A Figura 2 ilustra maiores valores de espalhamento associados a ventos inferiores a $6 \mathrm{~m} / \mathrm{s}$, especialmente aqueles gerados pelo MM5. Este espalhamento diminui na faixa 

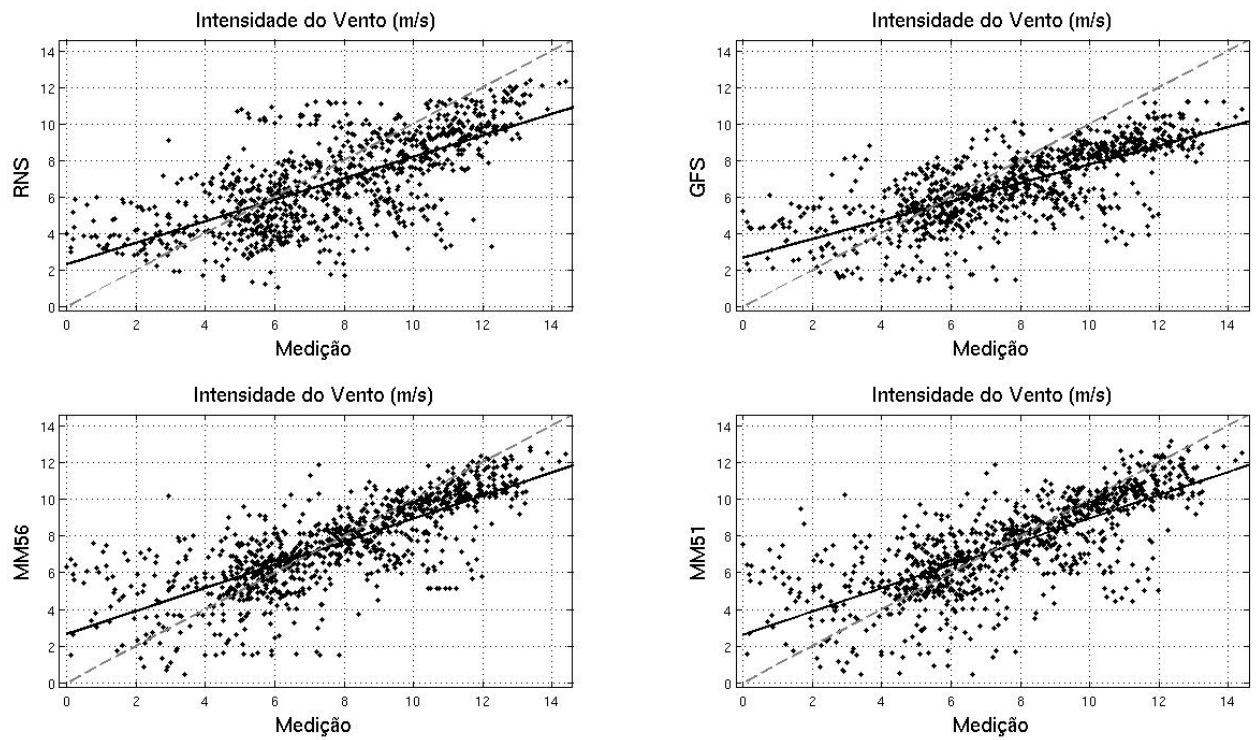

Figura 2 - Diagramas de espalhamento comparando dados de vento medidos e estimados pelos diferentes modelos meteorológicos. São mostradas a regressão linear (linha preta cheia) e a concordância perfeita (linha cinza pontilhada).

Tabela 3 - Valores dos parâmetros estatísticos médios utilizados para comparar as intensidades dos ventos estimados e medido.

\begin{tabular}{cccccc}
\hline & $\begin{array}{c}\text { Viés } \\
(\mathrm{m} / \mathrm{s})\end{array}$ & $\begin{array}{c}\text { Erro médio } \\
\text { quadrático } \\
(\mathrm{m} / \mathrm{s})\end{array}$ & $\begin{array}{c}\text { Índice de } \\
\text { espalhamento }\end{array}$ & Correlação & $\begin{array}{c}\text { Média } \\
(\mathrm{m} / \mathrm{s})\end{array}$ \\
\hline Medição & & & & & 7,6736 \\
RNS & $-0,8469$ & 2,3332 & 0,3041 & 0,6997 & 6,8266 \\
GFS & $-1,0772$ & 2,2931 & 0,2988 & 0,7363 & 6,5964 \\
MM56 & $-0,1973$ & 1,9189 & 0,2501 & 0,7703 & 7,4763 \\
MM51 & $-0,1880$ & 2,0213 & 0,2634 & 0,7458 & 7,4856 \\
\hline
\end{tabular}

entre 6 e $8 \mathrm{~m} / \mathrm{s}$ em todos os campos de vento. Comparando a regressão linear (linha preta) com a concordância perfeita, nota-se que os ventos modelados superestimam valores medidos até aproximadamente $6 \mathrm{~m} / \mathrm{s}$, a partir de onde estes são subestimados pelos modelos. Essas informações podem ser corroboradas observando a Figura 3, onde são calculados os valores estatísticos para cada faixa de intensidade do vento.

Como observado anteriormente, uma característica bastante clara é a semelhança entre o MM51 e o MM56, com valores ligeiramente maiores dos parâmetros por parte do MM51. Isto possivelmente justifica o melhor valor do índice de correlação do MM56 em relação ao MM51.

Da mesma forma como se observa na Figura 2, a distribuição do viés por faixas de intensidade do vento mostra que os modelos superestimaram os valores da medição até aproximadamente intensidades de $6 \mathrm{~m} / \mathrm{s}$. Vale também destacar o comportamento semelhante do RNS e GFS até aproximadamente $8,5 \mathrm{~m} / \mathrm{s}$, a partir de onde o segundo apresenta valores de viés mais negativos.

Em relação ao erro médio quadrático, nota-se que em faixas de vento menos intensos este valor é relativamente mais alto, quando comparado às demais faixas, e vai decaindo à medida que se aproxima de $4 \mathrm{~m} / \mathrm{s}$. Como observado na Figura 2 , entre as faixas de $4 \mathrm{~m} / \mathrm{s}$ e aproximadamente $8 \mathrm{~m} / \mathrm{s}$ ocorre uma maior aglomeração dos pontos, justificando os menores valores de erro médio quadrático nesta região.

Já o gráfico referente à distribuição do índice de espalhamento por faixas de velocidade ilustra valores bem próximos em praticamente todos os modelos. Observa-se que para intensidades de vento inferiores à aproximadamente 1 $\mathrm{m} / \mathrm{s}$ o índice de espalhamento apresenta maiores valores. Ao analisar a fórmula deste parâmetro, verifica-se que seu valor é proporcional ao RMSE e inversamente proporcional à média. Isto justifica o maior valor do erro médio quadrático na região inferior a $1 \mathrm{~m} / \mathrm{s}$. À medida em que se aumenta a velocidade do vento, vê-se que os valores do índice de espalhamento se apresentam próximo de 0 , devido aos maiores valores de média.

No gráfico da função densidade de probabilidade do vento modelado e medido (Figura 4) observa-se uma grande porcentagem de eventos acima de $6 \mathrm{~m} / \mathrm{s}$, velocidade a partir da qual os modelos tendem a subestimar a medição. $\mathrm{O}$ fato do MM51 e MM56, em relação aos demais modelos, subestimarem 

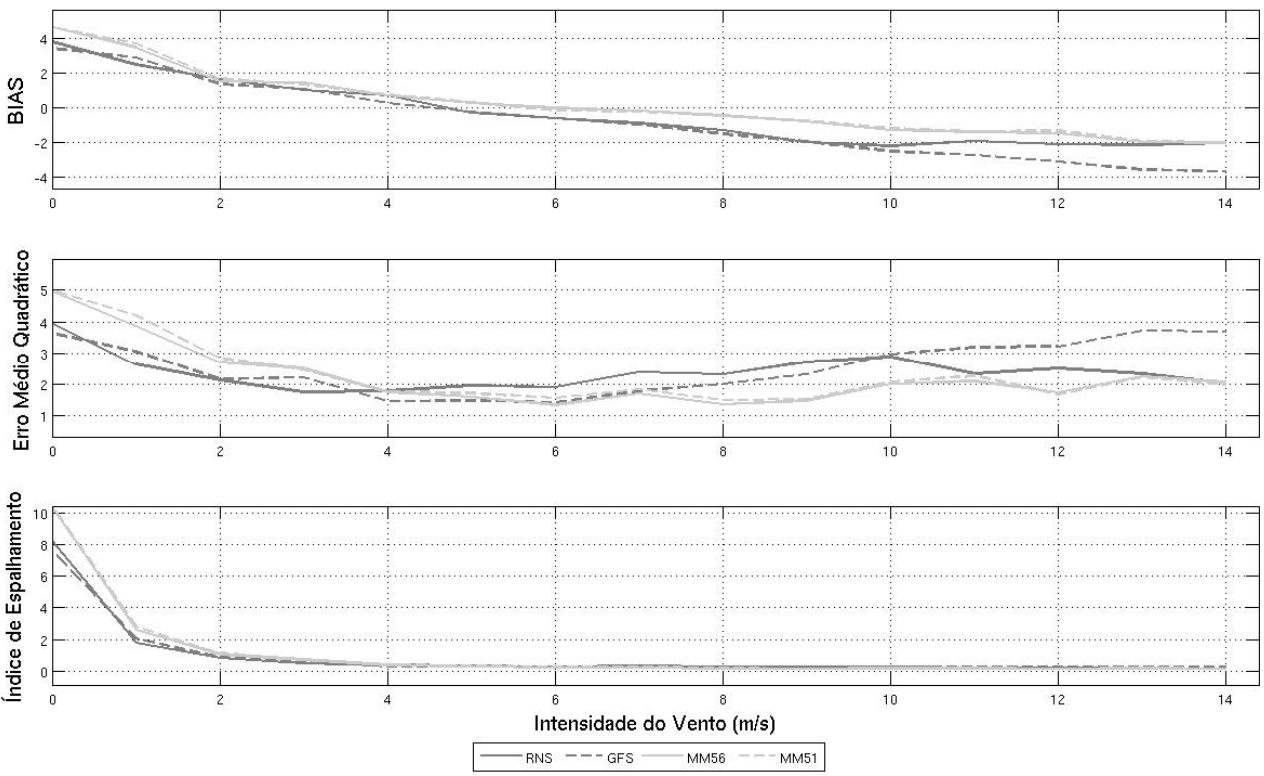

Figura 3 - Valores dos parâmetros estatísticos médios distribuídos por faixa de intensidade do vento.

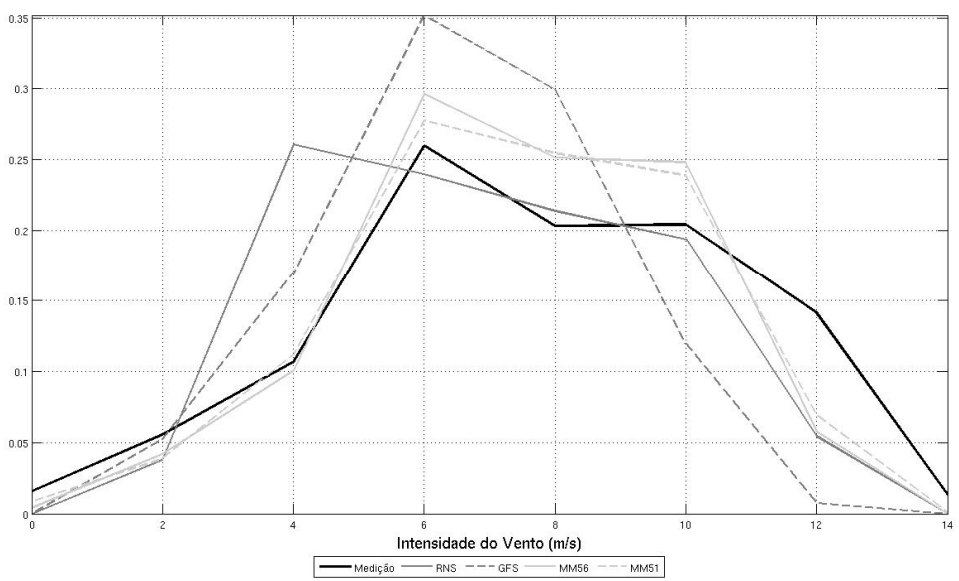

Figura 4 - Diagrama da função densidade de probabilidade das séries de intensidade de vento medidas e estimadas.

menos os ventos acima desta velocidade, justifica os menores valores de viés e maior proximidade do valor real da média (Tabela 1). Violante-Carvalho et al. (1997a) após analisarem 10 anos de dados medidos na mesma região verificaram uma distribuição bastante semelhante, com ocorrência predominante de ventos na faixa de 4 a $5 \mathrm{~m} / \mathrm{s}$.

\subsection{Avaliação dos dados de onda}

Como dito anteriormente, a avaliação da qualidade das estimativas feitas pelo WW3 é realizada através da sua comparação com medições realizadas pelo radar Miros em termos de altura significativa, período de pico e direção principal. A Figura 5 ilustra a evolução da altura significativa
(Hs), período associado ao pico de pico (Tp), e direção verdadeira associada ao pico primário $(\mathrm{Dp})$ medidos pelo radar. É interessante notar que esta figura apresenta um padrão bastante semelhante àquele mostrado na Figura 1 , com ondas predominantemente de N-NE e eventuais situações em que a direção muda para S-SE, como nos dias 07/01, 15/01, 21/01 e $05 / 02$.

A relação entre a direção do vento e a direção associada ao pico primário fica evidente nas Figuras 1 e 5 . O sincronismo entre as ondas e ventos de N-NE, aliada ao fato do Tp ser baixo durante estas ocasiões, indica que estas ondas foram formadas localmente. Além disso, nota-se que à medida que os ventos de $\mathrm{N}-\mathrm{NE}$ se intensificam, os valores de Hs aumentam, corroborando a hipótese acima. 

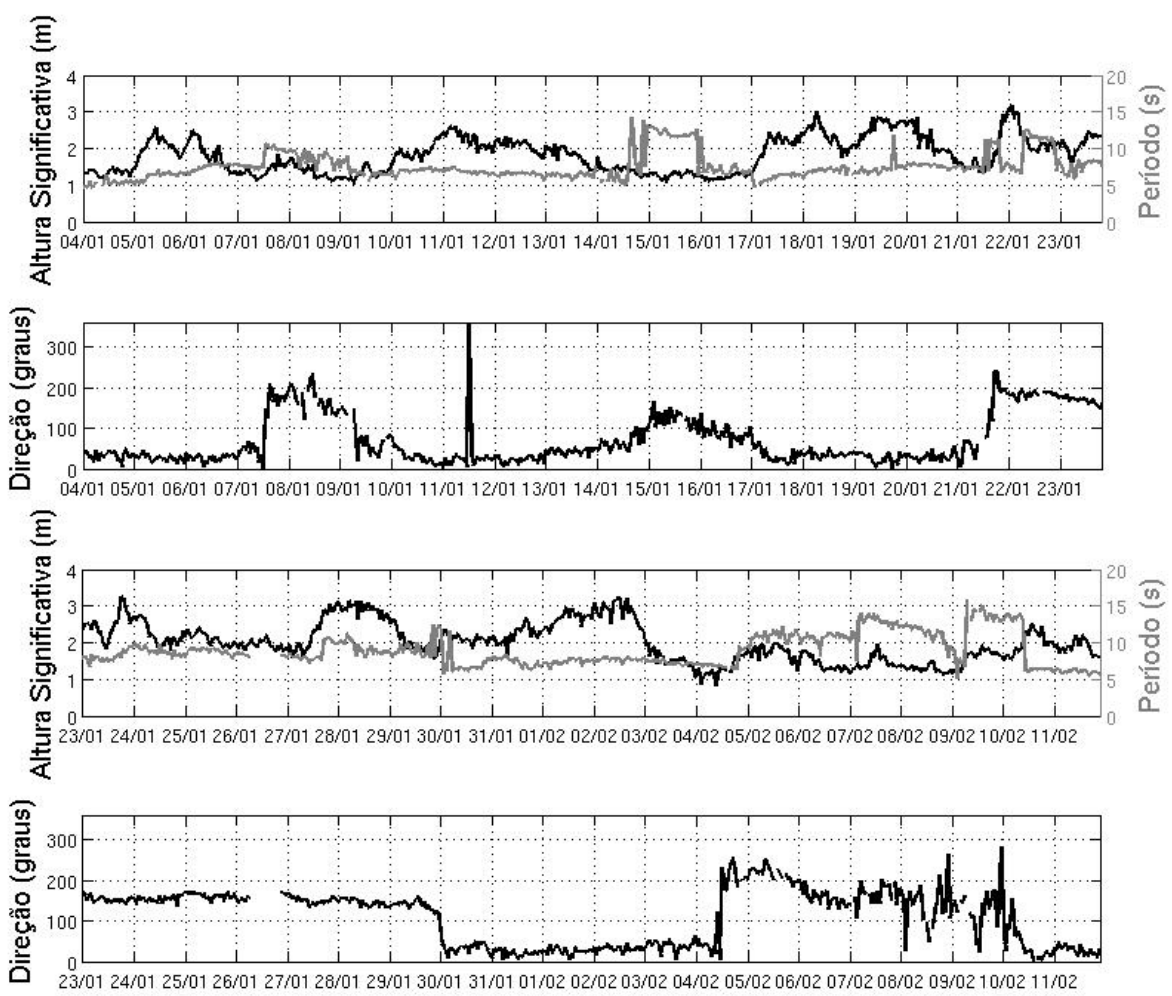

Figura 5 - Evolução temporal da altura significativa, período associado ao pico primário (Tp), e direção verdadeira associada ao pico primário (Dp) medidos pelo radar.

Adicionalmente, ao incidirem as ondas com direção associada ao pico primário de S-SE, verifica-se um aumento nos valores de período de pico e mudanças na direção e intensidade do vento em instantes próximos (Figura 5), característico de entradas de frentes frias nesta região. Com exceção do evento iniciado por volta do dia 21/01, observa-se uma diminuição dos valores de Hs durante entradas de frentes frias. Isso se explica pelo fato de estas ondulações terem sido formadas por centros de baixa pressão localizados a maiores distâncias da medição, como nos indicam os baixos valores de intensidade do vento (Figura 5) vindos de S-SE. Já o evento do dia 21/01 mostra valores maiores de Hs se comparados aos demais períodos. Observando os valores de $\mathrm{Tp}$ e intensidade do vento nesta direção, conclui-se que tais ondas tiveram sua área de geração mais próxima à medição comparativamente às demais. Tal padrão nesta região já foi reportado por diversos autores (Candella, 1997; Violante-Carvalho, 1998; Campos, 2009).

As Figuras 6 e 7 ilustram as estimativas do WW3 em termos de altura significativa, período de pico e direção principal associada ao pico primário. A Figura 6 apresenta características bastante semelhantes àquelas apresentadas na Figura 1, com um desempenho satisfatório nas quatro simulações. Assim como na simulação dos ventos, ressalta-se uma subestimação do modelo em relação à medição ao longo de quase todo o período de simulação, sendo o WMM51 e o WMM56 praticamente idênticos.

Maiores discrepâncias estão associadas ao WRNS, principalmente durante a entrada de ondas de baixa freqüência vindas de S-SE, como se observa na ondulação que chega por volta do dia 18/01. Swail e Cox (2000) atentam para o fato de ciclones extratropicais serem mal representados por modelos meteorológicos, principalmente a Reanálise/NCEP, devido à baixa resolução espacial e subestimação da energia. Adicionalmente, Marques da Cruz (2004) ao empregar o campo de vento da Reanálise/NCEP ao WW3 identificou um evento bastante semelhante a este, atribuindo tal resultado a um possível deslocamento da representação do centro de baixa pressão por parte do modelo atmosférico.

Observando a Figura 1, verifica-se que o RNS também subestima as estimativas durante este período, o que complementa a hipótese acima. $\mathrm{O}$ contrário acontece durante os eventos mais intensos associados a mares de N-NE, quando este representa melhor a condição real.

Ainda na Figura 6, fica clara também a similaridade apresentada entre o WGFS, WMM51 e WMM56, como observado na Figura 1. O mesmo pode ser observado na Figura 7, onde o período de pico e direção principal são bem semelhantes, com uma ligeira diferença entre os dois últimos e 

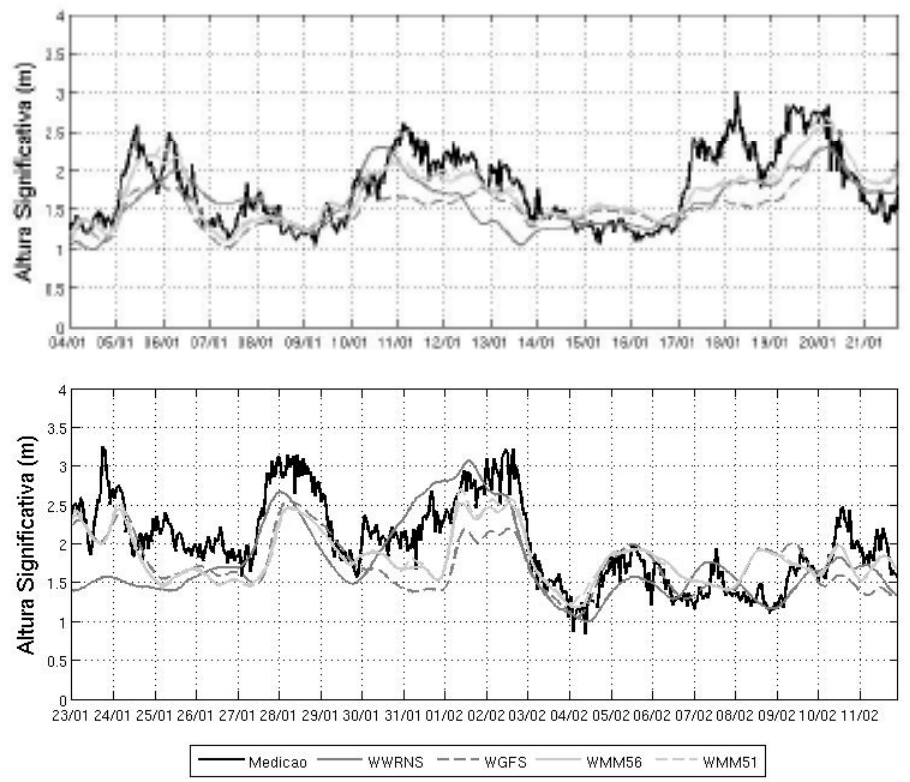

Figura 6 - Evolução temporal da altura significativa medida e estimada pelas simulações empregando os diferentes campos de vento.

o GFS em momentos de entrada de ondulação.

Corroborando a subestimação em relação às observações apresentadas na Figura 6, os parâmetros estatísticos calculados com séries temporais de 955 instantes para a variável altura significativa mostram valores de viés negativos em todas as simulações do WW3 (Tabela 4). Dentre elas, aquelas em que se utilizam o GFS e o MM51 apresentam o maior e menor valor, respectivamente. Em relação à correlação, os resultados se mostram próximos àqueles ilustrados na Tabela 3 , com uma melhora nos resultados da ordem de $9 \%$ ao utilizar um vento com maior resolução espaço-temporal. Mais uma vez o WMM56 e o RNS apresentam o melhor e pior resultado em relação aos demais, respectivamente. Quanto aos valores de índice de espalhamento, as quatro simulações fornecem valores próximos a $20 \mathrm{~cm}$, sendo que o WRNS e o WGFS são um pouco superiores $(23 \mathrm{~cm})$, enquanto o WMM51 e o WMM56 ficam em torno de $18 \mathrm{~cm}$.

Feng et al. (2006), empregando os ventos da Reanálise/ NCEP ao WW3 para a região equatorial e comparando os resultados a dados de altimetria, acharam valores de correlação e índice de espalhamento muito semelhante ao deste trabalho (0,68 e 0,19 m, respectivamente). Alves et al. (2009) realizaram um hindcast de nove anos de onda para a mesma região do presente estudo utilizando campos de vento do GFS como principal forçante. Os resultados foram satisfatórios comparando com as medições do Miros instalado no mesmo local, obtendo respectivamente o viés, RMSE, SI e correlação de 0,49 m, $0,47 \mathrm{~m}, 0,22 \mathrm{~m}$ e 0,79 . Vale destacar o diferente sinal de viés calculado neste trabalho e apresentado pelos referidos autores, sugerindo um distinto desempenho do modelo nas diferentes estações do ano, uma vez que os resultados aqui apresentados se referem somente ao verão. De forma similar à Figura 2, a Figura 8 ilustra os diagramas de espalhamento de Hs referentes a cada simulação.

Esta figura mostra que nas quatro simulações os maiores valores de espalhamento se concentram em regiões de maior altura significativa, sendo o WRNS a série que apresenta maiores distâncias em relação à concordância perfeita (linha pontilhada). Em todas as simulações observa-se uma maior concentração dos pontos em regiões entre $1,2 \mathrm{~m} / \mathrm{s}$ e $2,5 \mathrm{~m} / \mathrm{s}$. No que se refere à interseção entre as regressões lineares (linha cheia) e a concordância perfeita, a do WRNS e do WGFS se localizam próximos a $1,4 \mathrm{~m} / \mathrm{s}$, representando o limite entre a subestimação e a superestimação do modelo. Nos gráficos referentes ao MM51 e MM56 tal valor se localiza próximo a 1,6 m/s. Essas informações também estão claras na Figura 9, onde os parâmetros estatísticos são distribuídos por faixas de Hs.

Como citado ao longo do trabalho, a Figura 9 ilustra uma grande semelhança entre o MM51 e o MM56, principalmente para ondas acima de $1 \mathrm{~m}$. Todavia, a região do gráfico com ondas até esta altura nos mostra um desempenho ligeiramente melhor do MM56 em relação ao MM51, conforme os valores apresentados na Tabela 4. Da mesma forma se apresentam o WGFS e WRNS, onde os parâmetros estatísticos têm valores próximos a partir de aproximadamente 1,4 metros.

Adicionalmente, vale ressaltar a região próxima a 1,5 metros como a melhor representada pelas simulações, assim como vimos na Figura 8. A distribuição do viés por faixas de $\mathrm{Hs}$ mostra uma superestimação do modelo até este valor. Já valores 

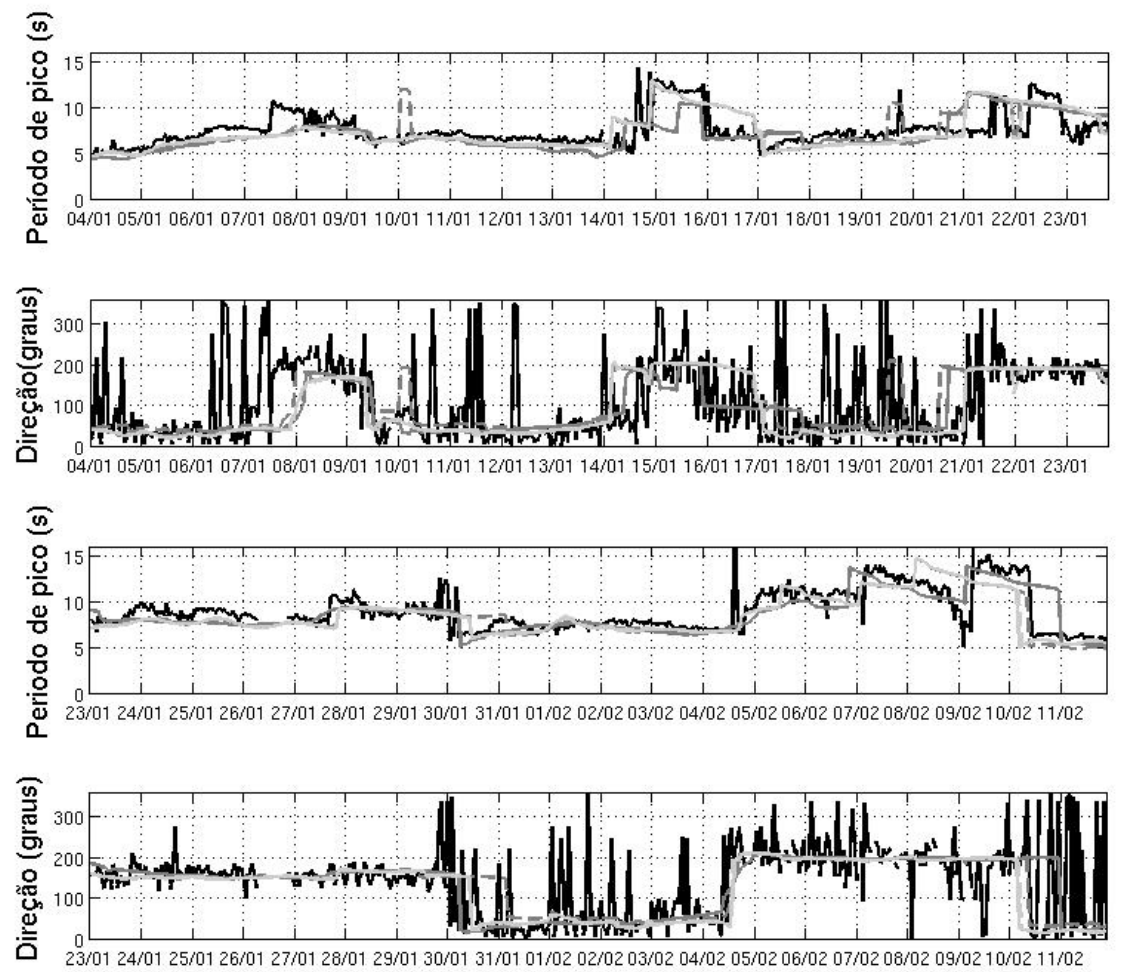

- Medição - RNS ---GFS - MM56 - MM51

Figura 7 - Evolução temporal do período de pico e direção principal associada aos períodos de pico medidos e estimados pelas simulações empregando os diferentes campos de vento.

Tabela 4 -Valores dos parâmetros estatísticos médios utilizados para comparar as alturas significativas estimadas e medidas

\begin{tabular}{lrllll}
\hline & Viés & $\begin{array}{r}\text { Erro médio } \\
\text { quadrático }\end{array}$ & $\begin{array}{c}\text { Índice de } \\
\text { espalhamento }\end{array}$ & Correlação & Média \\
\hline \multicolumn{1}{c}{ Medição } & & & & & 1,9091 \\
WRNS & $-0,2329$ & 0,4506 & 0,2360 & 0,6815 & 1,6762 \\
WGFS & $-0,2523$ & 0,4538 & 0,2377 & 0,6865 & 1,6568 \\
WMM56 & $-0,1363$ & 0,3583 & 0,1877 & 0,7784 & 1,7727 \\
WMM51 & $-0,1224$ & 0,3556 & 0,1863 & 0,7692 & 1,7867 \\
& & & & & \\
\hline
\end{tabular}

acima deste são subestimados pelo modelo. Esta superestimação do modelo para baixos valores de Hs também é relatada por Marques da Cruz (2004). Este autor também encontrou valores subestimados para ondas maiores por parte do modelo, assim como Bidlot et al. (2002) e Swail e Cox (2000).

No que tange ao erro médio quadrático, nota-se que os maiores valores estão associados às alturas significativas acima de 2 metros. Já os menores valores são encontrados em regiões próximas a 1,4 metros. Este mesmo padrão pode ser observado na Figura 8, onde os pontos aglomeram-se mais próximos à concordância perfeita nesta região e se espalham mais à medida que os valores de Hs aumentam. De forma bem semelhante se comporta o gráfico referente à distribuição do índice de espalhamento por faixas de Hs.

A Figura 10 ilustra a função densidade de probabilidade das séries temporais de altura significativa medida, bem como estimadas pelo modelo.

Nesta figura observa-se uma grande porcentagem de eventos com Hs acima de $1,5 \mathrm{~m} / \mathrm{s}$, altura a partir da qual os modelos tendem a subestimar a medição. O fato de o WMM51 e WMM56 apresentam um resultado melhor em regiões acima de $1,5 \mathrm{~m} / \mathrm{s}$ (Figuras 8 e 9), possivelmente justifica os melhores 

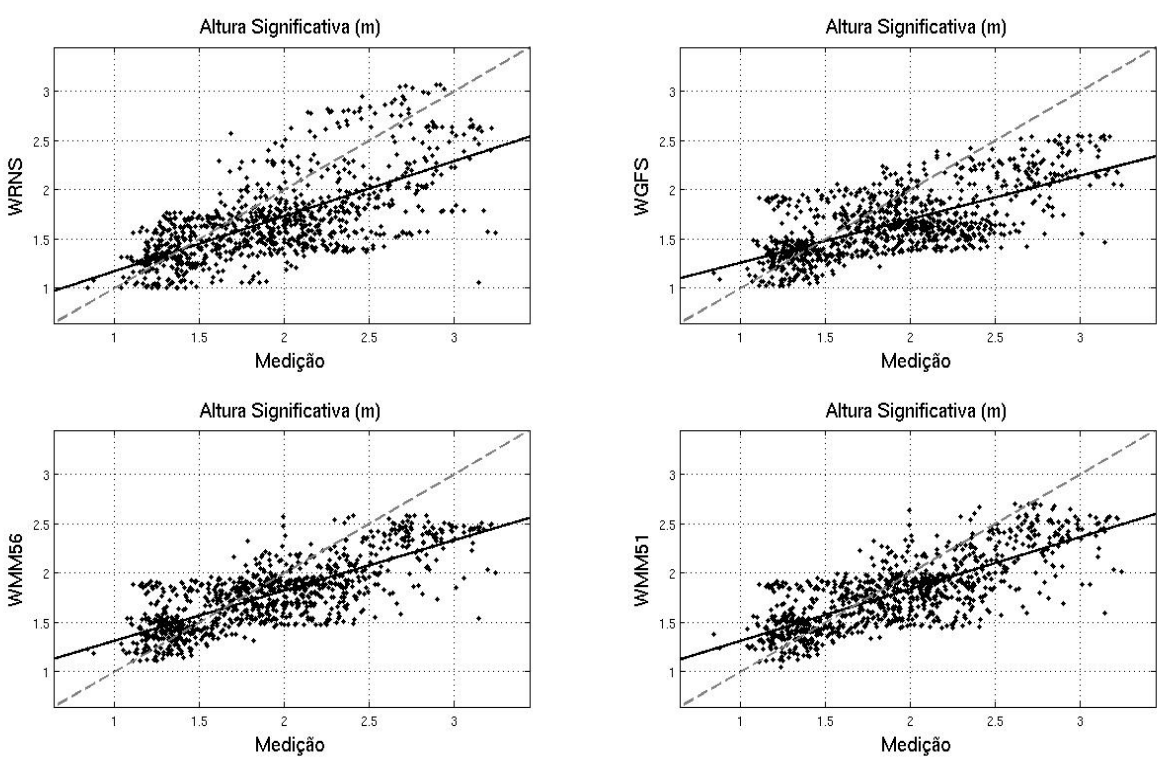

Figura 8 - Diagramas de espalhamento comparando dados de Hs medidos e estimados pelo ww3 empregando os diferentes campos de vento. São mostradas a regressão linear (linha cheia) e a concordância perfeita (linha pontilhada).
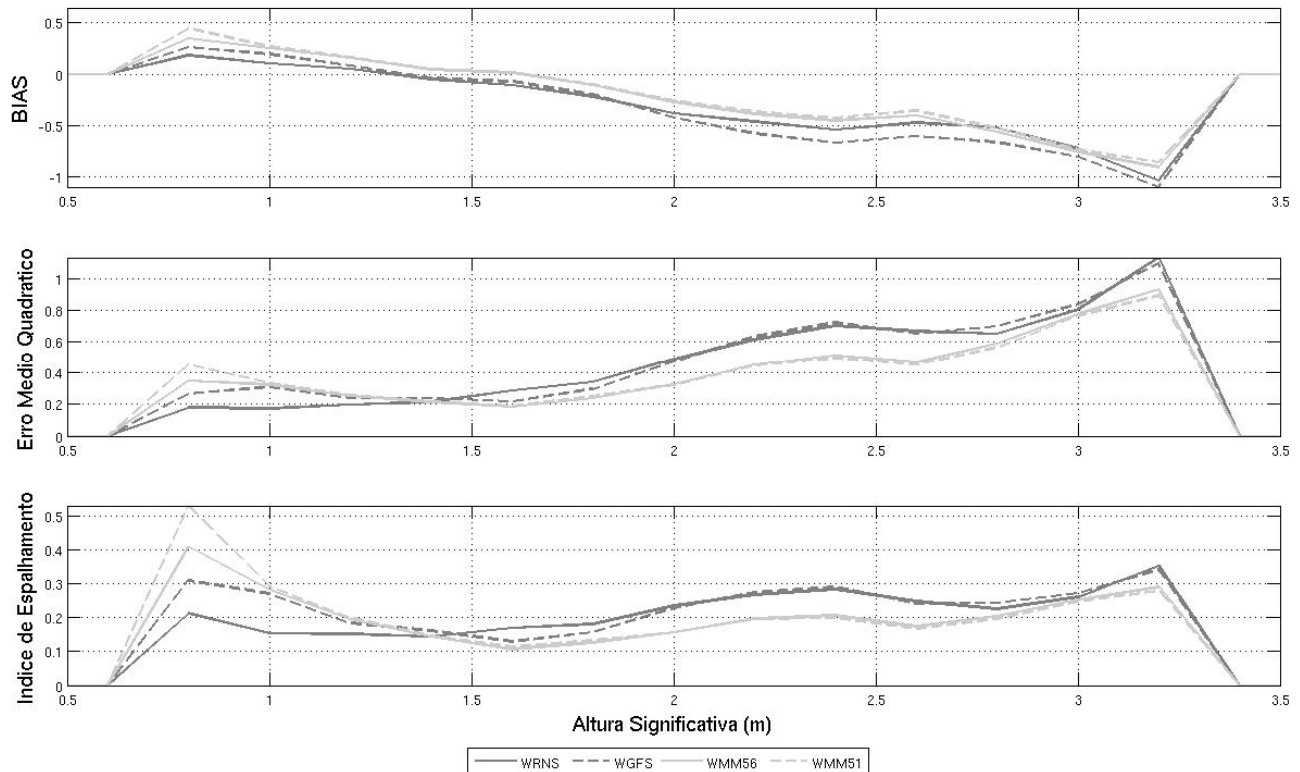

Figura 9 - Valores dos parâmetros estatísticos médios distribuídos por faixa de Hs.

valores estatísticos mostrados na Tabela 1. Tal distribuição está bem semelhante àquela apresentada por Violante-Carvalho et al. (1997b), onde observaram 60\% dos mares na Bacia de Campos com Hs entre 1 e 2 metros.

\section{CONCLUSÕES}

O presente estudo apresenta a reconstituição do estado de mar para a Bacia de Campos durante 42 dias, onde o objetivo é avaliar o impacto da utilização de ventos com diferentes resoluções espaciais e temporais para simulações numéricas de ondas. O período escolhido é devido à presença de ventos intensos na região de interesse, o que lhe confere bastante energia associada à alta freqüência, ao contrário da ondulação, presente ao longo de todo o ano na região. Isso torna este período bastante interessante do ponto de vista de simulações numéricas enfocando a geração de mar local, excluindo outros climas de onda que podem ser importantes num contexto mais abrangente. 


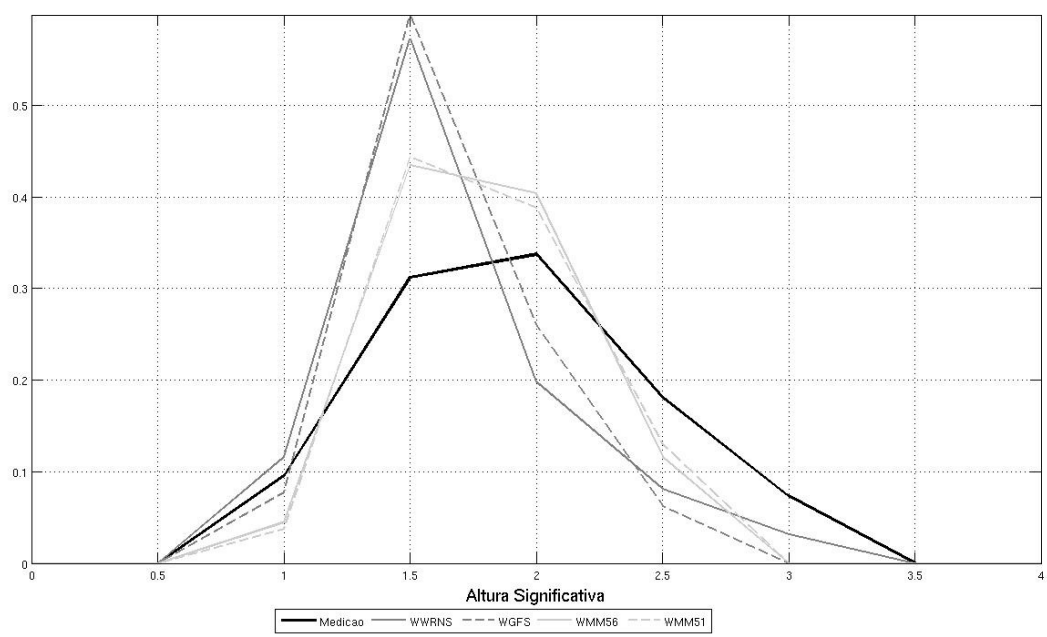

Figura 10 - Diagrama da função densidade de probabilidade das series de Hs medidas e estimadas pelo ww3 empregando os diferentes campos de vento.

São empregados quatro campos de vento com diferentes resoluções espaciais e temporais, cujos resultados foram posteriormente comparados às medições de onda realizadas por um radar instalado na região. Adicionalmente, os referidos campos de vento também são avaliados através da comparação com dados medidos por um anemômetro instalado no mesmo local. Apresentados e discutidos os resultados, pode-se concluir que:

- Apesar de uma ligeira subestimação, os modelos meteorológicos simulam de forma satisfatória os campos de vento, especialmente em períodos sob a influência do ASAS. Durante entradas de frente frias, porém, os modelos não apresentam o mesmo êxito, principalmente o RNS.

- Durante os mares mais severos associados às ondas de N-NE, a utilização dos campos de vento do MM5 proporciona melhores resultados se comparado ao WGFS e o WRNS. $\mathrm{O}$ fato deste modelo utilizar os produtos do GFS, como condição de contorno, indica que o esforço computacional para a geração de um campo de vento com alta resolução espacial e temporal é válido principalmente na representação do mar local nesta região.

- A similaridade entre o MM51 e o MM56 e as diferenças destes comparados com o GFS e o RNS conduzem a crer, que para as condições de verão na Bacia de Campos, a resolução espacial tem um papel mais importante em relação à resolução temporal no que tange ao desempenho dos modelos meteorológicos.

- De maneira geral, observa-se que os modelos meteorológicos utilizados apresentam uma faixa de melhor desempenho entre as intensidades 4 e $8 \mathrm{~m} / \mathrm{s}$. Ventos com intensidade de até aproximadamente $6 \mathrm{~m} / \mathrm{s}$ são superestimados pelos modelos e com velocidades superiores a este valor são subestimados.
- Assim como os modelos meteorológicos, o WW3 também apresenta resultados satisfatórios, apesar da ligeira subestimação da altura significativa. Maiores discrepâncias entre as simulações e a medição são quase sincronizadas com as deficiências dos modelos meteorológicos em representar a localização e evolução de ciclones extratropicais, principalmente o WRNS.

- Em termos de Hs, observa-se resultados ótimos próximo à região de $1,5 \mathrm{~m}$. Ondas acima deste valor são subestimadas pelo modelo. Faixas de maior Hs são mais bem representadas pelas simulações empregando os ventos do MM5.

\section{AGRADECIMENTOS}

Gostaríamos de agradecer à PETROBRAS pelos dados cedidos, fundamentais para a realização deste trabalho.

\section{REFERÊNCIAS BIBLIOGRÁFICAS}

ALVES, J. H. M., RIBEIRO, E. O., MATHENSON, G. S. G., LIMA, J. A., M., RIBEIRO, C. A. Reconstituição do clima de ondas no sul-sudeste brasileiro entre 1997 e 2005. Revista

Brasileira de Geofísica, v. 27, p.427 - 445, 2009.

ARDHUIN, F., BERTOTTI, L., BIDLOT, J. R., CAVALERI, L., FILIPETTO, V., LEFEVRE, J. M., WITTMANN, P. Comparison of wind and wave measurements and models in Western Mediterranean Sea. Ocean Engineering, v.34, p.526 - 541, 2007.

BAUER, E., WEISSE, R. Determination of high-frequency wind variability from observations and application to North Atlantic wave modeling. Journal of Geophysical Research. v.105, p.26179-26190, 2000. 
BIDlOT, J. R., HOLMES, D. J., WITTMANN, P. A., LALBEHARRY, R., CHEN, H. S. Intercomparison of the Performance of Operational Ocean Wave Forecasting Systems with Buoy Data, Weather and Forecasting, v.17, p.287-309, 2002.

CAMPOS, R. M. Análise dos extremos de onda no Rio de Janeiro associados a ciclones extratropicais no Atlântico Sul. Dissertação de Mestrado. COPPE/UFRJ, Rio de Janeiro, RJ, Brasil. 2009.

CANDELLA, R. N. Estudos de Casos de Ondas no Atlântico Sul através de Modelagem Numérica. Dissertação de Mestrado. COPPE/UFRJ, Rio de Janeiro, RJ, Brasil. 1997.

CAVALERI, L., BERTOTTI, L. The improvement of modelled wind and waves fields with increasing resolution. Ocean Engineering. v.33, p.553-565, 2006.

FENG, H., VANDERMARK, D., QUILFEN, Y., CHAPRON, B., BECKLEY, B. Assessment of wind -forcing impact on a global wind-wave model using the TOPEX altimeter. Ocean Engineering. v.33, p.1431-1461, 2006.

HASSELMANN, S., K. HASSELMANN, J. H. ALLENDER, T. P. BARNETT. Computations and parameterizations of the nonlinear energy transfer in a gravity-wave spectrum, Part II: parameterizations of the nonlinear energy transfer for application in wave models. Journal of Physical Oceanography. v.15, p.1378-1391. 1985.

HOLTHUiJSEN, L. H., BOOIJ, N., BERTOTTI, L. The propagation of wind errors through ocean wave hindcasts. Journal of offshore mechanics and artic engineeringtransactions of the asme. v.118, p.184-189, 1996.

KALNAY, E., et al. The NCEP/NCAR 40-Year Reanalysis Project. Bulletin of the American Meteorological Society. v.77, p.437 - 470, 1996.

KISTLER, R., et al. The NCEP-NCAR 50-Year Reanalysis: Monthly Means CD-ROM and Documentation. Bulletin of the American Meteorological Society. v. 82, p. 247 268, 2001.

KOMEN, G. J., CAVAlERI, L., DONELAN M., HASSELMANN, K., HASSELMANN, S., JANSSEN, P. E. A. M. Dynamics and Modelling of Ocean Waves. 1 ed. Cambridge, Cambridge University Press. 1994.

MARQUES DA CRUZ, L. M. Estudo comparativo de variações espaciais e temporais nas forçantes meteorológicas em um modelo de ondas de terceira geração no Oceano Atlântico Sul. Dissertação de Mestrado. COPPE/UFRJ, Rio de Janeiro, RJ, Brasil, 2004.
MENEZES, D. C. Contribuições Metodológicas para a Análise de Flutuações Atmosféricas e Oceanográficas de Baixa Freqüência na Costa do Estado do Rio de Janeiro. Dissertação de Mestrado. COPPE/UFRJ, Rio de Janeiro, RJ, Brasil, 2007.

PINHO, U. F. Caracterização de estados de mar na Bacia de Campos. Dissertação de Mestrado. COPPE/UFRJ, Rio de Janeiro, RJ, Brasil, 2003.

RUSU, L., BERNARDINO, M., SOARES, C. G. Influence of Wind Resolution on the Prediction of Waves Generated in an Estuary. Journal of coastal research. v. 2, p.14191423, 2009.

SWAIL, V. R., COX, A. T. On the Use of NCEP-NCAR Reanalysis Surface Marine Wind Fields for a Long-Term North Atlantic Wave Hindcast, Journal of Atmospheric and Oceanic Technology. v.17, p.532 - 545, 2000.

TEIXEIRA, J. C., ABREU, M. P., SOARES, C. G. Uncertainty of ocean wave hindcasts due to wind modeling. Journal of offshore mechanics and artic engineering-transactions of the asme, v.117, p.294 - 297, 1995.

TOLMAN, H .L. User manual and documentation of Wavewatch -III version 2.22. NOAA/NCEP. 2002.

TOLMAN, H. L., CHALIKOV, D. V. Source terms in a third-generation wind-wave model. Journal of Physical Oceanography. v.26, p.2497- 2518, 1996.

VIOLANTE-CARVALHO, N. Investigação sobre o clima de ondas da Bacia de Campos e a correlação com as situações meteorológicas associadas. Dissertação de Mestrado. COPPE/UFRJ, Rio de Janeiro, RJ, Brasil. 1998. VIOLANTE-CARVALHO, N.; NUNES, L. M. P., JÚNIOR, W. T. O clima de ondas da Bacia de Campos, Rio de Janeiro. Anais do XII Simpósio Brasileiro de Recursos Hídricos. p.403, 1997.

VIOLANTE-CARVALHO, N.; NUNES, L. M. P., JÚNIOR, W. T. O clima de ventos da Bacia de Campos, Rio de Janeiro. Anais do XII Simpósio Brasileiro de Recursos Hídricos. p.413, 1997a.

WANDI GROUP. The WAM Model - A Third Generation Ocean Wave Prediction Model. Journal of Physical Oceanography. v. 18, p. 1775-1810, 1988. 